\title{
Planulation in the Scleractinian Coral Pocillopora damicornis in Singapore Waters
}

\author{
L. M. Chou, B. P. L. Goh, and S. T. Quek
}

\begin{abstract}
Temporal patterns in the planulation of the scleractinian coral, Pocillopora damicornis (Linnaeus 1816), common on Singapore reefs were observed from August to November 1990. Widely distributed throughout the Indo-Pacific, the species is known to release planula larvae after internal fertilisation. At any one time, six colonies collected from the field were maintained in clear, sheltered outdoor aquaria and daily planula counts observed. Planulation was observed to be directly influenced by the lunar cycle, commencing 2 to 3 days before the new moon, peaking at around the new moon and ending close to the first quarter. This periodicity is similar to the planulation patterns observed in $P$. damicornis populations of the Central Pacific, particularly those of Palau, as well as the populations in the Great Barrier Reef during the Austral summer.
\end{abstract}

Index Terms-Planulation, Pocillopora damicornis, lunar cycle.

\section{INTRODUCTION}

Work on the reproductive cycles of coral populations in the equatorial waters of Singapore showed that many of the broadcasting species exhibited a seasonality [1]-[4] resulting in synchronous multispecies coral spawning, which is most dominant during the April full moon [5]. This study investigates the reproductive cycle of the scleractinian coral Pocillopora damicornis from Singapore reefs. The species was selected because it has been extensively studied in other higher latitude reefs and not much is known of its reproductive pattern closer to the equator.

Pocillopora damicornis produces large (approximately $1 \mathrm{~mm}$ in length) and abundant planula throughout the year [6]. Reproduction in reef corals via the release of planula larvae is often seen as a sexual process. Studies have shown that the planula larvae released by $P$. damicornis are produced by an asexual mechanism [7], [8] and it has also been suggested that sexual reproduction may occur through external fertilization [7].

The release rate of planulae in $P$. damicornis shows a cyclic component with a period of 29 days [9]-[13]. There are many natural phenomena that show a similar periodicity. A comparison of the Mean Daily Zurich Sunspot Number and time of $P$. damicornis planulation showed that peak larvae production coincided with periods of maximum sunspot

Manuscript received May 10, 2019; revised July 24, 2019.

L. M. Chou is with the Tropical Marine Science Institute, National University of Singapore, Singapore (e-mail: tmsclm@nus.edu.sg).

B. P. L. Goh is with the National Institute of Education, Nanyang Technological University, Singapore (e-mail: Beverly.goh@nie.edu.sg).

S. T. Quek is a former student with the Dept. of Biological Sciences, National University of Singapore, Singapore. number [14]. Another example is tidal cycles. The most accepted hypothesis is that planulation follows the lunar cycle. Night irradiance was the direct controlling factor of synchronous planulation [14].

Pocillopora damicornis is a widely distributed species. Major differences have been observed in life history characteristics between widely separated populations. A comprehensive review of the planulation patterns of the species from various geographic locations is provided [15]. In the Central Pacific (Palau), planulation occurs from before the new moon to the first quarter [10]. In Hawaii, it has been documented that planulation occurs from after the full moon to before the new moon for "Type Y" P. damicornis heads and from the first quarter to the full moon for "Type B" [13]. In the Great Barrier Reef, the species exhibits a phase shift in the time of planulation moving from winter to summer. In the Austral winter, planulation occurs during the full moon but in summer, during the new moon [16].

\section{MATERIALS AND METHODS}

Pocillopora damicornis colonies (Fig. 1) were observed for planulation from August 1990 through November 1990. At any one time, 6 colonies were kept for observation in outdoor aquaria with running seawater. Colonies of about $10 \mathrm{~cm}$ diameter were collected monthly from the fringing reefs of Singapore's southern offshore islands about 2 or 3 days after the lunar third quarter for the months of August, September and November, and two days before the full moon (lunar second quarter) for the month of October. They were transferred in aerated seawater to the laboratory and placed in holding tanks. The elapsed time from the removal of colonies from the reefs to their placement in the holding tanks was on average about an hour during which, care was taken to protect the colonies from undue stress.

Each colony was placed in a $33 \mathrm{~cm}$ diameter container with a spout, which channeled overflowing water into small collection cups with $170 \mu \mathrm{m}$ plankton mesh walls as described in [13]. Each container was supplied with fresh seawater at a flow rate of 3 l.min-1 daily from 0830 to 1530 hours. Due to the limited capacity of the seawater supply system at the laboratory between 1530 and 0830 hours, colonies were supplied with seawater at a rate of 3 1.min-1 circulated from within the holding tanks by an AC submersible pump. The holding tanks were kept under an open-sided shelter with a clear perspex roof.

Contents of the collection cups were washed into $170 \mu \mathrm{m}$ sieves after which, planulae present were transferred into glass bottles. Planulae were then counted and then released or kept for further study. The collection cups were examined 
daily for the presence of planulae, and the collection of planulae for counting was performed between 1600 and 1700 hours every day. Each batch of six colonies was monitored over one complete lunar cycle (29 days) with the exception of the two batches collected for the months of September and October. Corals collected for the September planulation were kept for 20 days until the end of the planulation period, before being replaced by the October colonies, which were monitored for 40 days until replacement by colonies collected for the November planulation.

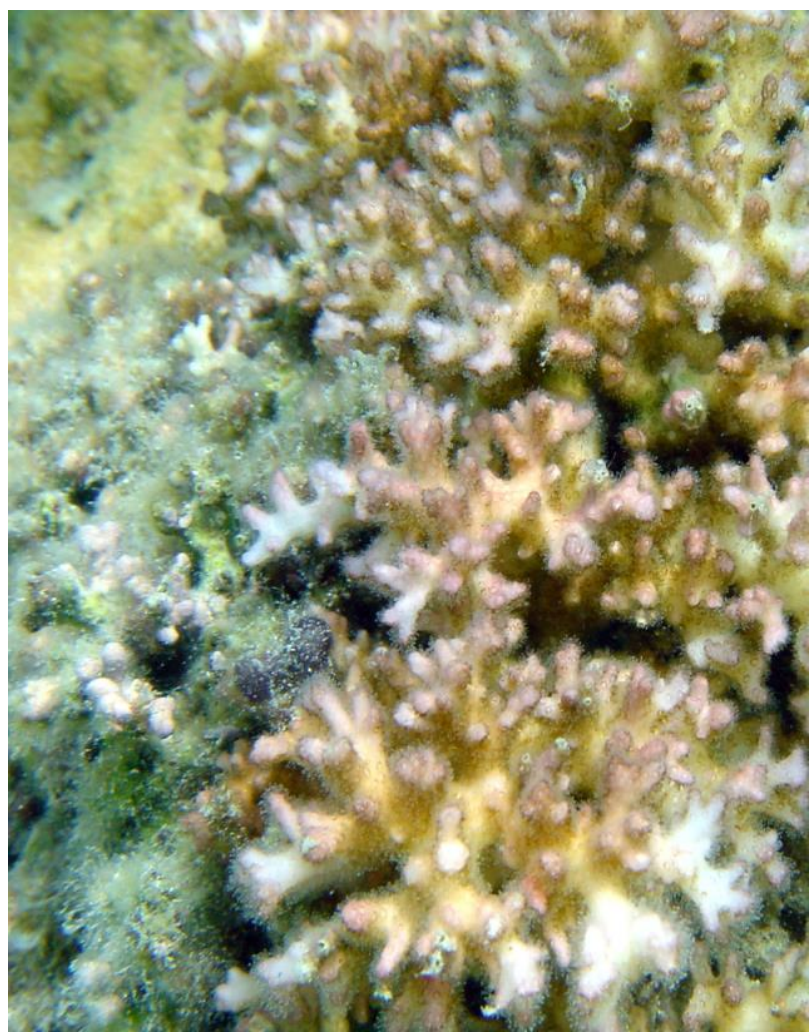

Fig. 1. A Pocillopora damicornis colony in a coral reef.

Both graphical and statistical analyses of the data were performed. For the graphical analysis, the log of the mean number of planulae produced by a colony on a given day plus one was plotted. The formula used was given by [13]:

$$
\log (\Pi+1)=\log (P / N+1)
$$

where $P$ is the total number of planulae released by all the study colonies on a given day, $N$ is the number of colonies and $\Pi$ is the mean number of planulae produced per day per colony. Statistical analyses involved the use of a two-way analysis of variance (ANOVA) on the data using the general linear model of the Statistical Analysis System (SAS) software package, with the month and the lunar age in days as the two defined classes. Significant differences in data were further analysed using Duncan's new multiple range test, an a posteriori test, to identify specific differences between months [17].

\section{RESULTS}

Planulation counts for the month of August began on 16 August, the 26th day of the lunar cycle. From henceforth, days of the lunar cycle will be prefixed by the letter "L", e.g. L1 is the first day of the lunar cycle. In the planulation pattern for the month of August (Fig. 2), planulae were first observed on L28 when a mean of 393.3 planulae per head per colony (П) was counted. The $\log (\Pi+1)$ value was 2.6 , and the count peaked on L1 (new moon), the third day of planulation, with $\Pi=1011.8$, and $\log (\Pi+1)=3.01$.

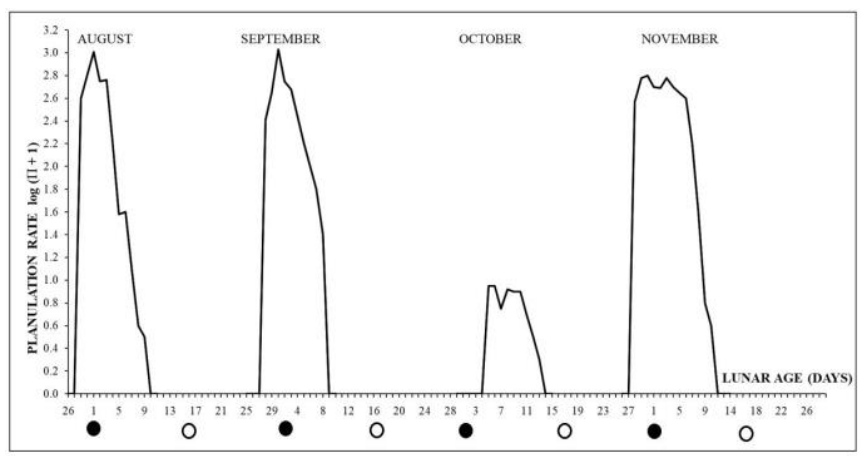

Fig. 2. Planulation pattern of Pocillopora damicornis in aquaria $(\bullet=$ new moon; $\mathrm{O}=$ full moon; dates in between indicate first or third quarter)

Planulae numbers dropped after this peak to $\Pi=563.8$ $(\log (\Pi+1)=2.75)$ on L2, followed by a narrow rise to $\Pi=$ $577(\log (\Pi+1)=2.76)$ on L3, before falling to $\Pi=37.2(\log$ $(\Pi+1)=1.58)$ on $L 5$. The planula count rose again narrowly to $\Pi=38.5(\log (\Pi+1)=1.6)$ on L6, after which the count fell steadily until planulation stopped on L10. Subsequent to this, no planulae were observed until L25, when the coral heads were replaced for the September planulation.

In the September cycle, planulae first appeared on L28 with $\Pi=255.3(\log (\Pi+1)=2.41)$. This reached a peak on $\mathrm{L} 1$, the fourth day of planulation, with $\Pi=1066.5(\log (\Pi+1)$ $=3.03$ ), and fell to zero on L9. No planulation was observed from L9 to L14.

For the October planulation, the colonies were collected on L14 instead of L25. Observation for planulation began on L15. However, planulae were not observed until L5 of the next cycle, when $\Pi=7.8(\log (\Pi+1)=0.95)$ was recorded. L6 yielded the same number of planulae. The planulation rate dropped to $\Pi=4.7(\log (\Pi+1)=0.75)$ on $L 7$, before rising to $\Pi=7.3(\log (\Pi+1)=0.92)$ on $L 8$, and then falling to zero on L14. Subsequently, no planulae were observed until the end of monitoring on L25.

The colonies collected for the November planulation were monitored from L26 through L25 of the following cycle. Planulation began on L28 with $\Pi=374.8(\log (\Pi+1)=2.57)$, peaking on L30 with $\Pi=634(\log (\Pi+1)=2.8)$. This rate fell to $\Pi=486.2(\log (\Pi+1)=2.69)$ on L2, and then rose to $\Pi=599.5(\log (\Pi+1)=2.78)$ on L3 before falling to zero on L12 when planulation ceased. After this, no planulae were observed and monitoring was terminated on L26.

For the months of August, September and November, planulation began on the 28th day (L28) of the lunar cycle whereas for October, L5 marked the beginning of planulation. Planulation peaked on L1 (new moon) for August, on L30 for the months of September and November, and L5 and L6 in October. The August planulation yielded an average of 3560 planulae per colony for the whole lunar cycle, with each colony releasing an average of 1011.8 planulae on the day of 
the planulation peak. Similarly, an average of 3565.5 planulae were counted per colony for September with the count reaching 1066.5 per colony on the day of peak planulae production. Planulation patterns for August, September and November showed consistencies in the following aspects: spawning began four or five days after the last quarter, peaked on or one day before the first day of the new moon (L1) and ended at around the lunar first quarter. Also, there was only one period of planulation for each lunar cycle without any smaller scale planulations in between.

In contrast, the colonies collected for the October planulation released an average of only 46.7 planulae per colony for the entire time they were monitored, and peaked at only 7.8 planulae per colony on the day of maximum planulation. Statistical analyses revealed that the October planulation cycle was atypical in comparison to the other three planulation cycles in aspects like timing of planulation commencement and peak, and the total number of planulae produced. Two-way ANOVA on the planulation data showed a significant difference between months $(F=8.87 ; d f=3,15$; $p<0.0001)$, while Duncan's test showed that there was no significant difference between the months of August, September and November, but the planulation cycle for October was significantly different from the other three months $(p<0.05)$.

\section{DISCUSSION}

Results showed that for the duration of this study, the planula release rates of $P$. damicornis populations in Singapore follows a cyclical pattern. As in other geographical locations, the planulation of local populations follows a lunar cycle of 29.4 days.

Planulation consistently commenced 2 or 3 days before the new moon and ceased at around the lunar first quarter. The planulation periods lasted from 11 days to 2 weeks. The planulation of local populations is compared with that of other geographical locations (Table I). Singapore populations exhibit the same planulation pattern as that of the Central Pacific populations, particularly those of Palau where $P$. damicornis populations began spawning before the new moon, peaked at around the new moon and stopped spawning by the time of the first quarter [10]. Studies in the Great Barrier Reef also show that $P$. damicornis populations follow this pattern during the Austral summer when planulation peaks at the new moon, a shift from a full moon peak in the Austral winter [16].

Planulation peaks of $P$. damicornis populations from the various geographical locations have been reported for practically all phases of the lunar cycle (Table I). Studies conducted in the different geographical locations were however carried out during different years, using different methods and sometimes produced incomplete data sets [13].

These impose some uncertainty and even invalidity for comparisons between different locations based on such data. Because of these considerations, it is pertinent to ask if the reported phase differences in planulation peaks are consistent with the different geographical locations, or if the populations are in worldwide synchrony but undergoing phase shifts from year to year. With regard to Enewetak in the Marshall Islands, and Hawaii, the question was answered by [13]. Their study involved simultaneous daily measurement of planulation at both sites, employing more or less similar methods. They found that there was indeed a phase difference in the timing of planulation between populations in Enewetak and the "Type $\mathrm{Y}^{\prime}$ and "Type B" morphological variants in Hawaii. They suggested that the geographically isolated populations of $P$. damicornis have through time undergone phase shifts by natural selection in order that planulations coincide with some favourable set of conditions, the time of which may differ at different locations.

TABLE I: TIMING OF PlanUlation OF P. DAMICORNIS FROM DifFERENT GEOGRAPHICAL LOCATIONS. EACH LUNAR CYCLE IS DIVIDED INTO EIGHT PHASES: 1 = NEW MOON, 3 = FIRST QUARTER, 5 = Full MOON, 7 = LAST QUARTER; 2, 4, 6, 8 REPRESENT INTERMEDIATE LUNAR PHASES

\begin{tabular}{ll}
\hline \hline Location & Lunar phase of planulation \\
\hline Singapore & $8-3$ \\
Central Pacific & \\
$\quad$ Palau & $8-3$ \\
$\quad$ Enewetak & $2-3$ \\
Hawaii & \\
$\quad$ Type B & $3-5$ \\
$\quad$ Type Y & $6-8$ \\
Great Barrier Reef & \\
$\quad$ Summer & 1 \\
$\quad$ Winter & 5 \\
\hline \hline
\end{tabular}

The studies so far carried out on the temporal distribution of planula release have involved either the daily replacement of the subject colonies or the use of only one set of colonies for the entire duration of the study. It was established that the timing and intensity of daily planula release were not significantly influenced by the frequency at which the parent colonies were replaced, provided they were kept in adequate conditions [13], [14]. In this study, the parent colonies were replaced once each lunar cycle. It was not possible to change the colonies daily because of the time and difficulty involved, neither was it possible to use only one set of colonies for the entire study as the aquarium system that was used could not provide adequately favourable conditions for the corals over an extended duration. This was apparent when it was observed that after about four weeks, the condition of the coral heads began to deteriorate. A loss of green and yellow pigmentation with partially retracted polyps was observed. It was therefore unlikely that the colonies could maintain normal planulation patterns for periods lasting more than a single lunar cycle. This was also the reason for collecting the corals only a few days before planulation began to ensure that the corals were in a healthy state during the period of planulation.

The results showed the October planulation to be different from that of the other 3 months in timing and total number of planulae released. The most likely reason for this was that the October colonies were collected two days before the full moon which was almost two weeks before the projected commencement of spawning. Exposure to the less than ideal conditions in the aquarium system may have stressed the corals, causing a delay in the timing of planulation and a drastic drop in the number of planulae produced. It was observed that the planulae produced were much smaller than normal and almost colourless, indicating the absence of 
symbiotic zooxanthellae, which affords the planulae the brown to dark brown colouration. This is consistent with other reports on aborted planulae in corals subjected to stress or some extreme environmental disturbance [14].

A recent molecular study [18] of Pocillopora corals in Singapore indicated that most Pocillopora damicornis-like corals are in fact Pocillopora acuta (Lamarck 1816). Molecular sequence data of sixteen Pocillopora samples from Singapore reefs analysed in the study revealed the presence of $P$. acuta but not $P$. damicornis. We are unable to verify if the specimens that were worked on for this paper are $P$. acuta and not $P$. damicornis.

\section{CONCLUSION}

This study was performed over a period of only four months. Thus the conclusions that can be drawn from the results are only applicable to these four months. A more exhaustive study lasting at least a year in duration would be required. Such a study would establish whether or not the populations undergo phase changes from one lunar cycle to another as is the case with Great Barrier Reef populations. This is however unlikely, given the absence of distinct seasons in Singapore.

\section{CONFLICT OF INTEREST}

The authors declare no conflict of interest.

\section{AUTHOR CONTRIBUTIONS}

The research was conducted by ST Quek under the supervision of BPL Goh and LM Chou. Planula counts were done by ST Quek and data analysis verified by BPL Goh. All three authors contributed to the writing of this paper.

\section{ACKNOWLEDGMENT}

The authors are grateful to the Department of Biological Sciences, National University of Singapore for the support and facilities, both field and laboratory that enabled this investigation.

\section{REFERENCES}

[1] J. R. Guest, A. H. Baird, B. P. L. Goh, and L. M. Chou, "Seasonal reproduction in equatorial reef corals," Invertebrate Reproduction and Development, vol. 48, pp. 207-218, 2005.

[2] J. R. Guest, A. H. Baird, B. P. L. Goh, and L. M. Chou, "Reproductive seasonality in an equatorial assemblage of scleractinian corals," Coral Reefs, vol. 24, pp. 112-116. 2005.

[3] J. R. Guest, B. P. L. Goh, and L. M. Chou, "Sexual systems in scleractinian corals: an unusual pattern in the reef-building species Diploastrea heliopora," Coral Reefs, vol. 31, pp. 705-713, 2012.

[4] J. R. Guest, L. M. Chou, and B. P. L. Goh, Reproductive seasonality of the reef building coral Platygyra pini on Singapore reefs," Raffles Bulletin of Zoology, supplement 25, pp. 115-123, 2012.

[5] J. R. Guest, L. M. Chou, A. H. Baird, and B. P. L. Goh, "Multispecific, synchronous coral spawning in Singapore," Coral Reefs, vol. 21, pp. 422-432, 2002.

[6] C. H. Edmondson, "Behavior of coral planulae under altered saline and thermal conditions," Occasional Papers Bernice P. Bishop Museum, vol. 18, pp. 283-304, 1946.

[7] J. A. Stoddart, "The asexual production of planulae in the coral, Pocillopora damicornis," Marine Biology, vol. 76, pp. 279-284, 1983.

[8] M. C. Chavez, "Gametogenesis and origin of planulae in the hermatypic coral Pocillopora damicornis," Coral Reef Population Biology, Hawaii Institute of Marine Biology, 1986, pp. 193-205.
[9] S. M. Marshall and T. A. Stephenson, "The breeding of reef animals Part 1. The corals," Scientific Reports Great Barrier Reef Expedition of British Museum Natural History, vol. 3, pp. 219-245, 1933.

[10] K. Atoda, "The larva and postlarval development of some reef-building corals. 1. Pocillopora damicornis (Dana)," Scientific Reports Tohoku University, vol.18, pp. 24-47.

[11] J. Harrigan, "The planula larva of Pocillopora damicornis, lunar periodicity of swarming and substratum selection behavior," $\mathrm{Ph} . \mathrm{D}$. dissertation, University of Hawaii, 1972.

[12] J. S. Stimson, "Mode and timing of reproduction in some common hermatypic corals of Hawaii and Enewetak," Marine Biology, vol. 48, pp. 173-184, 1978.

[13] R. H. Richmond and P. L. Jokiel, "Lunar periodicity in larva release in the reef coral Pocillopora damicornis at Enewetak and Hawaii," Bulletin of Marine Science, vol. 34, pp. 280-287, 1984.

[14] P. L. Jokiel, R. Y. Ito, and P. M. Liu, "Night irradiance and synchronization of lunar spawning of larvae in the reef coral Pocillopora damicornis (Linnaeus)," Marine Biology, vol. 88, pp. 164-174, 1984.

[15] R. H. Richmond and C. L. Hunter, "Reproduction and recruitment of corals: Comparisons among the Caribbean, The Eastern Pacific, The Indo-West Pacific, and the Red Sea," Marine Ecology Progress Series, vol. 60, pp. 185-203, 1990 .

[16] V. J. Harriot, "Reproductive seasonality, settlement and post-settlement mortality of Pocillopora damicornis (Linnaeus), at Lizard Island, Great Barrier Reef," Coral Reefs, vol. 2, pp. 151-157.

[17] D. B. Duncan, "Multiple range and multiple F tests," Biometrics, vol. 11, pp. 1-42, 1955.

[18] R. C. Poquita-Du, C. S. L. Ng, B. J. Loo, L. Afiq-Rosli, Y. C. Tay, P. A. Todd, L. M. Chou, and D. Huang, "New evidence shows that Pocillopora 'damicornis-like' corals in Singapore are actually Pocillopora acuta (Scleractinia: Pocilloporidae)," Biodiversity Data Journal, vol. 5, p. e11407, 2017.

Copyright $\odot 2019$ by the authors. This is an open access article distributed under the Creative Commons Attribution License which permits unrestricted use, distribution, and reproduction in any medium, provided the original work is properly cited (CC BY 4.0).

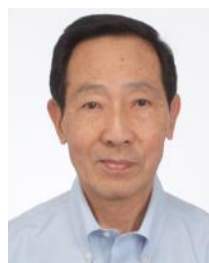

Chou L. M. was born in Singapore. He completed four years of high school in Sydney, Australia. He studied in University of Singapore and graduated with B.Sc. honours (first class) degree in 1969 and the Ph.D. (zoology) in 1975.

He retired in 2014 after 37 years of service to the National University of Singapore and became adjunct research professor at the University's Tropical Marine Science Institute from 2014 to 2019.

Prof. Chou's research on coral reef biology and integrated coastal management covers Southeast Asia and he coordinated and edited the "2009 State of the Marine Environment Report for the East Asian Seas" for the United Nations Environment Programme. His current research focus is reef restoration with a particularly interest in how corals can be re-established in highly turbid conditions of rapidly developing coastal areas. Since 1998, he has actively contributed to the regular regional compilation of the health of coral reefs for the "Status of Coral Reefs of the World" reports published by the Australian Institute of Marine Science and the "Status of Coral Reefs of East Asia" published by Japan's Ministry of the Environment. He is currently an Honorary Fellow of the Singapore Institute of Biology and a Fellow of the Singapore National Academy of Science.

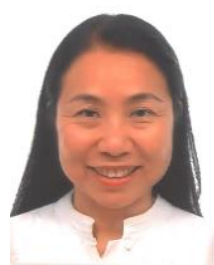

Goh B. P. L. was born in Singapore. She completed primary, secondary and tertiary education in Singapore. She graduated with a BSc (zoology) honours (second upper) from the National University of Singapore in 1987. She obtained an MSc (tropical coastal management) from the University of Newcastle Upon Tyne, U.K. (1988), and a PhD (zoology) from the National University of Singapore in 1995.

She was the project manager in the International Global Change START Programme (Southeast Asia Secretariat) from 1994 to 1996. She held various concurrent posts at the National University of Singapore from 1997 to 2001 : research fellow, Tropical Marine Science Initiative (1997 - 2000), programme coordinator, masters in environmental management programme (1999 - 2000), teaching fellow $(2000-2001)$. She has been a faculty member at the National Institute of Education, Nanyang Technological University, Singapore since 2001, and is currently senior lecturer, and assistant head (MSc life sciences programme) at the Natural Sciences and 
Science Education Academic Group at NIE, NTU. Her research interests include marine ecotoxicology, marine ecology, environmental biology and citizen science. Her publication: Goh, B.P.L., Lai, C.H., Tan, L.T., Yap, N.W.L. and Dissanayake, A. Handbook of Marine Ecotoxicology Techniques (Singapore: National Institute of Education, Nanyang Technological University, National Parks Board, 2014) is used as a key reference to engage adults, teachers and pupils from Singapore Secondary
Schools in citizen science activities relating to marine conservation and management.

Dr. Goh is a Fellow of the Singapore Institute of Biology (F. S. I. Biol). She was awarded the National Institute of Education Excellence in Teaching Commendation in 2017. 